\title{
Introduction to IBM marketing suite
}

The papers in this section of the journal were submitted either as part of my own process for encouraging publication of good research material in the broad area of customer relationship management (CRM), or as part of the IBM-sponsored conference, Business Innovation in the Knowledge Economy (BIKE), held at IBM Warwick on 12th June, 2002. This conference had four streams:

- customer relationship management

- finance and risk after 11th September

— public sector support for e-innovation

- small firms, the Internet and new technology adoption.

The aim of both efforts was to ensure that practitioners involved in the implementation of CRM and e-business, or advising private or public sector clients thereon, have access to the good material coming out of universities and companies. The conference was the second of its kind, the first having been held at IBM Warwick in December, 2001.

IBM's involvement originated in the growing realisation in IBM that much of the material about CRM and e-business that had made its way to the desks of senior managers had crossed the line that divides sensible analysis and/or prediction from hype. The worst of this material was described in the consulting profession as 'burning platform' material - the image being of the client on a burning platform. The implied choice was get off the burning platform or be roasted alive. As it turned out, the only things that got burnt in most cases were the budget and the budget holder's fingers.

While it is recognised that the role of academics and consultants is partly to be 'thought leaders', this does not mean being what became described as 'thought bleeders'. While consultants may have congratulated themselves in the short term on the sales they made from encouraging clients to spend far too much on e-business or CRM systems, in the long term all one can say about the situation is, buyer beware. If a company is foolish enough to have bought from a consultancy with a strong public reputation for using lots of inexperienced people to recommend why and how it should change, it has only itself to blame. Indeed, the blame often attaches to the board directors who signed off the budgets and who, in regrettably few cases, lost their jobs because of major programme failure.

Academics, on the other hand, are supposed to have a different responsibility. Bearers of the standard of truth, able to point to evidence to justify their assertions, they should be above accusations of telling the story the hearer likes to hear. As academic rewards have declined, however, academics themselves have to market their ideas, to gain funding for research projects or to make 
consultancy incomes. This leads to a clear conflict of interest, which is made particularly severe by the trust often placed in them by senior managers when assailed with a variety of consulting offers.

The result, when one asks academics and thinking practitioners to submit papers reflecting the reality of the world of e-business and CRM, tends to be an interesting combination of solid research showing the state of the world, or forecasting how it is likely to be, and of papers challenging concepts that provide the foundation for this analysis and forecasting. As our annual conference develops, we are attracting ever-larger numbers of participants, from a widening range of universities and companies. It is pleasing to note that the academics do not fall nicely into consulting categories. For example, one of the best papers (it received the best paper award for the financial category and is being considered for publication in the Journal of Financial Services Marketing as we went to press) described a geographic analysis to investment in people, facilities and systems by financial services companies, and identified the risk to offices or facilities located far from the decision-making headquarters and focusing on a very specific topic (eg customer service call centres, centres for marketing analysis).

The particular group of papers featured in this section have a common theme the importance of companies matching their capability to manage data and/or interaction with customers with the companies' model of doing business. This is always hard to do, and no companies can claim perfection, partly because business models themselves need to evolve to keep pace with changes in technology, competitive challenges and customer needs. What is obvious is that failure to do so can lead to data or contacts going out of control, or being too expensive to manage, or suffering in quality. Incrementality of approach now seems to be the favoured option in CRM and e-business, with good programme management providing a strong underpinning, and allowing a company to take stock of where it is supposed to be at any one time, and what sort of performance it should be looking for from its capabilities (people, organisational structure, processes, systems, data, measurement etc.).

MERLIN STONE Editorial Board July 2002 